\title{
Endringer i forskningsaktiviteten ved Universitetssykehuset Nord-Norge 2000-2005
}

\author{
Bjørn Odvar Eriksen og Elin Evensen \\ Klinisk forskningssenter, Universitetssykehuset Nord-Norge, 9038 Tromsø \\ Korrespondanse: Bjørn Odvar Eriksen, Klinisk forskningssenter, Postboks 78, Universitetssykehuset Nord-Norge, 9038 Troms $\varnothing$ \\ Telefon 77628391 Telefaks 77669136 E-post: bjorn.odvar.eriksen@unn.no
}

\begin{abstract}
SAMMENDRAG
Bakgrunn: Norsk medisinsk forskning hevder seg dårlig i nordisk sammenheng. Ved Universitetssykehuset Nord-Norge (UNN) ble forskningsaktivitet og hindringer for klinisk forskning undersøkt med en spørreskjemaundersøkelse i år 2000. Denne undersøkelsen er nå gjentatt etter fem år for å se om forholdene er endret.
\end{abstract}

Materiale og metode: Alle leger og psykologer ved UNN fikk i mai 2005 tilsendt det samme spørreskjemaet som ble brukt i år 2000.

Resultater: Etter purring hadde $433(82 \%)$ av 530 spurte svart. $48 \%$ deltok i et pågående forskningsprosjekt (38\% i et prosjekt som kvalifiserte til medforfatterskap, 5\% i et prosjekt initiert av industrien, $5 \%$ i begge typer prosjekter). $22 \%$ av de spurte oppgav å ha doktorgrad, $28 \%$ hadde publisert i fagfellevurdert tidsskrift uten å ha doktorgrad, mens $28 \%$ ikke hadde publisert i slike tidsskrifter. Av faktorer som hindret forskning eller økt forskningsaktivitet, angav $84 \%$ mangel på tid, $52 \%$ faktorer som potensielt kunne avhjelpes av sykehusets apparat for forskningsstøtte og $35 \%$ andre faktorer. Uttrykt i prosentandeler var det små endringer i svarene i forhold til år 2000.

Fortolkning: Det har ikke skjedd noen endring i andelen ansatte engasjert i forskning ved UNN fra 2000 til 2005. Fortsatt oppleves mangel på tid som den viktigste hindringen for forskning.

Norsk medisinsk forsknings beskjedne posisjon sammenlignet med resten av Norden har vært gjenstand for debatt $\mathrm{i}$ en årrekke $(1,2)$. Forskjellige årsaker er blitt påpekt og tiltak foreslått (3-6). Fortsatt rangeres den imidlertid lavest på de fleste skalaer sammenlignet med våre naboland (7). Ved statens overtakelse av spesialisthelsetjenesten i 2001 var det meningen at forskningen skulle få et løft. De øremerkede midlene til forskning ble økt, og de regionale helseforetakene utarbeidet forskningsstrategier (8). Man planlegger nå å øke ressurstilgangen til medisinsk forskning vesentlig $i$ årene som kommer (5).

Ved Universitetssykehuset Nord-Norge (UNN) ble det i år 2000 gjennomført en spørreskjemaundersøkelse om forskningsaktiviteten blant alle psykologer og leger (9). Vi ønsket å gjenta undersøkelsen i 2005 med det formål å finne ut om aktiviteten hadde økt. Spørreskjemaet tok også sikte på å undersøke hvilken rolle sykehusets forskningsstøtte-enheter spilte for å fremme forskning. I år 2000 var konklusjonen at disse enhetene var nødvendige, men ikke tilstrekkelige forutsetninger for å øke forskningsaktiviteten. Et overveldende flertall av de spurte angav mangel på tid som det viktigste hinderet for forskning (9). Ved å gjenta undersøkelsen ville vi også undersøke endringer mht. disse forholdene.

\section{MATERIALE OG MEtoder}

I mai 2005 ble det samme spørreskjemaet som i 2000 sendt ut på nytt, med kun ubetydelige endringer. Det inneholdt spørsmål om kjønn, yrke, type avdeling, ev- entuell universitetstilknytning og forskningsbakgrunn med hensyn til doktorgrad og publikasjoner i tidsskrifter med fagfellevurdering. Universitetstilknytning ble definert som ansettelse i hoved- eller bistilling eller engasjement som stipendiat. I tillegg ble det stilt spørsmål om pågående forskningsprosjekter og forhold som ble opplevd å være til hinder for økt forskningsaktivitet. Egen forskning ble definert som deltagelse i prosjekter på medforfatter-nivå. Et spørsmål om deltagelse i forskningsprosjekt initiert av industrien var også med.

Spørreskjemaet ble sendt ut til i alle psykologer og leger med fast ansettelse i hoved- eller bistilling på UNN på undersøkelsestidspunktet. Leger i tidsbegrensede stillinger ble regnet som fast ansatte. Turnusleger, vikarer og ansatte som var i permisjon på undersøkelsestidspunktet, ble ikke inkludert. Spørreskjemaet ble besvart anonymt.

Informasjon om avdelingstilhørighet, stilling og kjønn for hele populasjonen av leger og psykologer ble innhentet fra personalarkivet og opplysninger om avlagt doktorgrad fra Doktorgradsregisteret ved Norsk institutt for studier av forskning og utdanning (NIFU) (Tabell 1). Det ble antatt konstant respons-sannsynlighet for personene innen hver gruppe definert ved kombinasjoner av disse variablene, og en respons homogen gruppe-modell ble brukt for å estimere antallet svar i hver kategori for hele populasjonen (10). Dette innebar at hver besvarelse ble vektet med den inverse av svarandelen i hver gruppe. Dette ble gjort separat for undersøkelsene i 2000 og 2005. 
For å lette sammenligningen mellom de to undersøkelsene er resultatene fra begge sammenstilt i tabeller og angitt som estimater for de to totalpopulasjonene.

Kriteriene for inndeling i avdelingstyper og yrkeskategorier var noe endret fra 2000 til 2005, og dataene fra 2000 er derfor kodet om for disse variablene for å lette sammenligningen.

\section{RESUltater}

Av UNNs 530 leger og psykologer, hadde 433 besvart spørreskjemaet etter purring (svarandel 0,82). På spørsmålet om tilknytning til Universitetet i Tromsø var det flere som angav tilknytning enn man kunne finne igjen på det medisinske fakultets personelloversikter. Årsaken kan ha vært at disse oversiktene var ufullstendige eller at UNN-ansatte med annen forbindelse til universitet enn angitt i spørsmålet har svart positivt. Dette spørsmålet ble derfor holdt utenfor analysene.

Tabell 1 sammenligner avdelingstilhørighet, yrkesgruppe, kjønn og status mht. doktorgrad hos utvalget som har besvart spørreskjemaet med hele populasjonen. Tilsvarende data fra undersøkelsen i 2000 er angitt for sammenligning. Det bemerkes en økning i det totale antall leger og psykologer på $35 \%$ fra 2000 til 2005 og en økning i kvinneandelen fra 35 til $41 \%$. Økningen i personell er spesielt kraftig for klinisk psykiatriske avdelinger og for psykologer, noe som skyldes at flere psykiatriske enheter ble innlemmet i UNN ved den statlige overtakelsen av spesialisthelsetjenesten. Antallet personer med doktorgrad har økt, men prosentandelen er omtrent uendret.

\section{Forskningsbakgrunn}

Av overlegene hadde 34\% doktorgrad, 32\% ikke doktorgrad men publikasjon i tidsskrift med fagfellevurdering, mens $34 \%$ ikke hadde noen slik publikasjon. For underordnede leger og psykologer var andelene uten noen publikasjon betraktelig høyere (Tabell 2). Sammenlignet med 2000 er det kun ubetydelige forskjeller $i$ andelene $i$ de ulike svarkategoriene.

\section{Forskningsaktivitet}

Andelen ansatte som angir å delta i noen form for forskningsprosjekt falt fra 53\% i år 2000 til 48\% i 2005 (Tabell 3). Dette skyldes hovedsakelig et fall i andelen personer som driver både egen og industriinitiert forskning fra 11 til 5\%. For dem med doktorgrad viser de tilsvarende tallene en reduksjon fra 19 til $14 \%$.

Andelen ansatte som ikke ønsker å forske selv om forholdene blir lagt til rette for det, ligger stabilt på ca. $14 \%$.

\section{Hindringer for forskning}

Hindringer for forskning ble delt inn i hovedkategoriene "mangel på forskningsstøttefunksjoner" (dvs. mangel på funksjoner som tilbys av forskningsstøtteenhetene Klinisk forskningssenter og Nord-norsk psykiatrisk forskningssenter), "mangel på tid" og "andre faktorer". Tabell 4 viser at fordelingen av svarene i 2005 var svært lik den i 2000, selv når man ser på enkeltspørsmål innen hver kategori. Fortsatt er mangel på tid pga. andre arbeidsoppgaver den dominerende faktoren.

\section{Tabell 1. Sammenligning mellom dem som har besvart spørreskjemaet og alle spurte i år 2000 og} 2005

\begin{tabular}{|c|c|c|c|c|c|c|c|c|}
\hline & \multicolumn{4}{|c|}{ År 2000} & \multicolumn{4}{|c|}{ År 2005} \\
\hline & \multicolumn{2}{|c|}{ Besvarte spørreskjema } & \multicolumn{2}{|c|}{ Alle spurte } & \multicolumn{2}{|c|}{ Besvarte spørreskjema } & \multicolumn{2}{|c|}{ Alle spurte } \\
\hline & Antall & $(\%)$ & Antall & (\%) & Antall & (\%) & Antall & (\%) \\
\hline \multicolumn{9}{|l|}{ Type avdeling } \\
\hline Klinisk somatisk & 189 & (65) & 270 & (69) & 279 & (64) & 325 & (61) \\
\hline Klinisk psykiatrisk & 38 & (13) & 43 & (11) & 79 & (18) & 116 & (22) \\
\hline Medisinsk serviceavdeling & 54 & (19) & 77 & (20) & 60 & (14) & 87 & (16) \\
\hline Annet & 8 & (3) & 3 & (1) & 15 & (3) & 2 & $(0)$ \\
\hline \multicolumn{9}{|l|}{ Yrkesgruppe } \\
\hline Overordnet lege & 159 & (55) & 220 & (56) & 232 & (54) & 276 & $(52)$ \\
\hline Underordnet lege & 118 & (41) & 160 & (41) & 145 & (33) & 174 & (33) \\
\hline Psykolog & 12 & (4) & 13 & (3) & 56 & (13) & 80 & (15) \\
\hline Doktorgrad & 84 & $(29)$ & 91 & (23) & 97 & (22) & 115 & $(22)$ \\
\hline \multicolumn{9}{|l|}{ Kjønn } \\
\hline Mann & 187 & (65) & 257 & (65) & 259 & $(60)$ & 315 & (59) \\
\hline Kvinne & 102 & (35) & 136 & (35) & 174 & (40) & 215 & (41) \\
\hline Totalt & 289 & $(100)$ & 393 & $(100)$ & 433 & $(100)$ & 530 & (100) \\
\hline
\end{tabular}




\section{Klinisk somatiske avdelinger}

Den klinisk psykiatriske delen av UNNs virksomhet har gjennomgått store endringer ved at nye enheter er lagt inn under helseforetaket. Siden dette i mindre utstrekning har skjedd innen somatikken, var det av spesiell interesse å undersøke endringer for disse avdelingene. Analysene ovenfor ble derfor gjentatt for denne undergruppen. Ingen vesentlige avvik fra mønsteret $\mathrm{i}$ besvarelsene $\mathrm{i}$ totalmaterialet ble funnet.

\section{DISKUSJON}

Spesialisthelsetjenesten har gjennomgått omfattende strukturelle endringer i løpet av siste femårsperiode. UNN har ekspandert kraftig, først og fremst ved at tidligere selvstendige enheter er blitt lagt inn under helseforetaket. Kravet om forskning i spesialisthelsetjenesteloven må imidlertid oppfattes å gjelde hele organisasjonen, slik at en ambisjon om å øke forskningsaktiviteten må innebære at forskning skal utgjøre en større andel av foretakets totale aktivitet. Bedømt ut fra andelen leger og psykologer med pågående forskningsprosjekter ser det ikke ut til at UNN har nærmet seg dette målet i perioden 2000 til 2005, selv om det absolutte antallet personer som forsker, har økt (tabell $3)$. Det er heller ingen endring når det gjelder de spurtes forskningskompetanse uttrykt ved andel som oppgir å ha doktorgrad eller publikasjoner i fagfellevurderte tidsskrifter (tabell 2). En tredjedel av de overordnede legene har doktorgrad, mens en tredjedel ikke har noen forskningserfaring. Dette er uendret fra år 2000.

Mønsteret i faktorer som angis å hindre forskning, var i hovedsak det samme i 2005 som i 2000. Mangel på tid pga. andre arbeidsoppgaver er fortsatt den dominerende faktoren og angis av i overkant av $80 \%$. Det er naturlig å se dette i forhold til de effektiviserings- og nedbemanningsprosessene sykehuset har vært gjennom i perioden. Fra flere hold er det blitt uttrykt bekymring for at dette spesielt ville ramme forskningsaktiviteten (11).

Tidsmangelen overskygger de andre to hovedkategoriene hindringer, men hele $52 \%$ angav mangel på faktorer som omfattes av de tjenestene forskningsstøtteapparatet ved UNN tilbyr, og som det derfor faktisk ikke er mangel på. Et av tiltakene for å styrke forskningen ved sykehuset har nettopp vært en omorganisering og opprusting av disse funksjonene. I 2000 hadde UNN et kompetansesenter for klinisk forskning, en egen sengepost for klinisk forskning og et kontor for klinisk kreftforskning. I 2003 ble det vedtatt å samle disse funksjonene i et klinisk forskningssenter for å oppnå synergieffekter. På den psykiatriske siden har man hele tiden hatt en enhet for psykiatrisk forskning. Disse enhetene har hatt et ansvar for forskningsstøtte i hele Helse Nord og har også arbeidet med infrastrukturelle tiltak for å styrke forskningen i regionen. At forskere fortsatt angir mangel på forskningstøtte som et problem, kan bety at disse enhetene ikke har vært gode nok til å markedsføre sine tjenester.

Tabell 2. Forskningsbakgrunn i forhold til yrkesgruppe ${ }^{1}$.

\begin{tabular}{|c|c|c|c|c|c|c|c|c|}
\hline & \multicolumn{2}{|c|}{ Doktorgrad } & \multicolumn{2}{|c|}{$\begin{array}{l}\text { Ikke doktorgrad, men } \\
\text { publikasjon i tidsskrifter } \\
\text { med fagfelle-vurdering }\end{array}$} & \multicolumn{2}{|c|}{$\begin{array}{l}\text { Ingen publikasjoner i } \\
\text { tidsskrifter med fagfelle- } \\
\text { vurdering }\end{array}$} & \multicolumn{2}{|c|}{ Totalt } \\
\hline & Antall & $(\%)$ & Antall & $(\%)$ & Antall & $(\%)$ & Antall & (\%) \\
\hline \multicolumn{9}{|l|}{ År 2000} \\
\hline \multirow{4}{*}{$\begin{array}{r}\text { Overordnet lege } \\
\text { Underordnetlege } \\
\text { Psykolog }\end{array}$} & 73 & (33) & 73 & (33) & 74 & (34) & 220 & (100) \\
\hline & 17 & (11) & 38 & (24) & 106 & (66) & 160 & (100) \\
\hline & 1 & (8) & 2 & (13) & 10 & (79) & 12 & (100) \\
\hline & 91 & (23) & 112 & (29) & 189 & (48) & 393 & (100) \\
\hline
\end{tabular}

\section{Âr 2005}

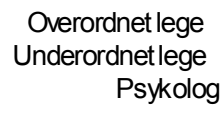

Totalt

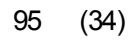

15 (9)

5 (6)

$115 \quad(22)$
$88 \quad(32)$

$45 \quad(26)$

12 (15)

$146 \quad(28)$
93 (34)

114 (65)

63 (78)

$269 \quad(51)$
$276 \quad(100)$

$174 \quad(100)$

$80 \quad$ (100)

$530 \quad(100)$ 
En opptelling av antall personer med pågående forskningsprosjekter kan ikke fange opp endringer i forskningsaktiviteten hos den enkelte forsker eller i forskningens kvalitet. Dette er en svakhet ved undersøkelsen. Likevel synes det rimelig å anta en positiv samvariasjon mellom disse størrelsene slik at endringer $\mathrm{i}$ antall personer som forsker kan tjene som en indikator på endringer i forskningsproduksjonen totalt. Resultatene bekreftes også i noen grad av andre mål på forskningsaktivitet fra samme periode. NIFUs beregning av publikasjonspoeng for Helse Nord, hvorav UNN produserer en dominerende andel, endret seg ubetydelig fra 155,1 i perioden 2001-2003 til 154,7 i perioden 2002-2004 (12). Fordi det totale antall publikasjonspoeng på landsbasis økte i samme periode, medførte dette en reduksjon i Helse Nords andel av de øremerkede statlige forskningsmidlene. Antall søk- nader om prosjekter innen feltet klinisk anvendt forskning til Regional etisk komité Nord har i perioden 2000-2004 ligget konstant rundt 30 (13). Selv om disse indikatorene ikke bare representerer universitetssykehusets forskning, bidrar de i noen grad til å understøtte resultatene av spørreskjemaundersøkelsen.

På bakgrunn av undersøkelsen fra år 2000 er det ikke overraskende at satsingen på forskningsstøttefunksjonene ved UNN ikke har gitt økt forskningsaktivitet. En av konklusjonene den gang var at det var "... lite sannsynlig at økt innsats fra de tre (forskningsstøtte)enhetene vil kunne føre til særlig økt forskningsaktivitet uten at forholdene også legges til rette på andre måter. ..." (9). Mangel på tid til forskning var også da det dominerende hinderet for å oppnå dette. Den kraftige økningen i antallet leger og psykologer $i$ mellomtiden er allokert til kliniske arbeidsoppgaver.

Tabell 3. Deltagelse i pågående forskningsprosjekter i forhold til forskningsbakgrunn ${ }^{1}$.

\begin{tabular}{|c|c|c|c|c|c|c|c|c|c|}
\hline & & \multicolumn{2}{|c|}{ Doktorgrad } & \multicolumn{2}{|c|}{$\begin{array}{l}\text { lkke doktorgrad, } \\
\text { men publikasjon i } \\
\text { tidsskrifter med } \\
\text { fagfelle-vurdering }\end{array}$} & \multicolumn{2}{|c|}{$\begin{array}{c}\text { Ingen } \\
\text { publikasjoner i } \\
\text { tidsskrifter med } \\
\text { fagfelle-vurdering }\end{array}$} & \multicolumn{2}{|c|}{ Totalt } \\
\hline & & Antall & $(\%)$ & Antall & $(\%)$ & Antall & $(\%)$ & Antall & $(\%)$ \\
\hline \multicolumn{10}{|c|}{ År 2000} \\
\hline \multicolumn{10}{|c|}{ Deltar i pågående prosjekt } \\
\hline & Kun eget prosjekt & 57 & (63) & 48 & (42) & 37 & (20) & 142 & $(36)$ \\
\hline & Kun industri-initiert prosjekt & 3 & (3) & 7 & (6) & 14 & (7) & 23 & (6) \\
\hline & Begge & 19 & (21) & 17 & (15) & 8 & (4) & 44 & $(11)$ \\
\hline \multicolumn{10}{|c|}{ Deltar ikke i pågående prosjekt } \\
\hline & Ønsker å forske & 10 & (11) & 34 & (30) & 83 & (44) & 127 & $(32)$ \\
\hline & Ønsker ikke å forske & 2 & (3) & 8 & $(7)$ & 48 & (25) & 58 & $(15)$ \\
\hline Totalt & & 91 & $(100)$ & 112 & $(100)$ & 189 & $(100)$ & 393 & (100) \\
\hline \multicolumn{10}{|c|}{ År 2005} \\
\hline \multicolumn{10}{|c|}{ Deltar i pågående prosjekt } \\
\hline & Kun eget prosjekt & 82 & (71) & 65 & (44) & 52 & (19) & 199 & (38) \\
\hline & Kun industri-initiert prosjekt & 4 & (4) & 10 & (7) & 14 & (5) & 29 & (5) \\
\hline & Begge & 14 & $(12)$ & 10 & $(7)$ & 3 & (1) & 27 & (5) \\
\hline \multicolumn{10}{|c|}{ Deltar ikke i pågående prosjekt } \\
\hline & $\varnothing$ nsker å forske & 14 & (12) & 49 & (33) & 136 & (50) & 199 & $(37)$ \\
\hline & $\varnothing$ nsker ikke å forske & 0 & (0) & 12 & $(8)$ & 65 & (24) & 77 & $(14)$ \\
\hline Totalt & & 115 & $(100)$ & 146 & $(100)$ & 269 & $(100)$ & 530 & $(100)$ \\
\hline
\end{tabular}


Man må anta at tidsmangelen kunne ha vært avhjulpet noe dersom noen av disse ressursene hadde blitt omdirigert til forskning.

For legenes vedkommende kan dette skje ved opprettelse av stillinger øremerket for forskning. Mye tyder på at D-stillinger og stillinger for kombinert forskning og spesialistutdanning kan være velegnet på underordnet nivå $(14,15)$. Økt bruk av slike stillinger kan også bidra til å motvirke problemene med å rekruttere unge leger til forskning (2). Lignende stillinger bør også opprettes på post-doktoralt nivå. Det ideelle ville være en situasjon der kliniske forskere kunne trekke seg ut av klinisk arbeid i perioder for å arbeide fulltid med forskning, i motsetning til å forske ved siden av kliniske plikter. Dette er trolig en forutsetning for å produsere forskning av tilfredsstillende kvalitet.

Det har skjedd en reduksjon i prosentandelen som arbeider med prosjekter initiert av industrien fra $17 \% \mathrm{i}$ 2000 til 10\% i 2005 (tabell 3). Reduksjonen har først og fremst skjedd ved andelen ansatte som driver både egen- og industriinitiert forskning har gått ned. Denne trenden er spesielt uttalt for forskere med doktorgrad, der mange av dem som tidligere holdt på med oppdragsforskning nå ser ut til å konsentrere seg om egen forskning. Den samme trenden ses i andelen søknader om legemiddelutprøvninger regnet $i$ prosent av alle søknader om klinisk anvendt forskning til Regional etisk komité Nord som har falt fra 33\% i 2000 til 21\% i 2004. De tilsvarende prosentandelene på landsbasis var 37 og 24\% (13). En av årsakene kan være at det er blitt lettere å finansiere egne prosjekter med offentlige midler, slik at man ikke i samme grad er avhengig av inntekter fra oppdragsforskning. Gitt en viss forskningskapasitet på universitetssykehusene, er en økning av andelen egeninitiert forskning en ønsket utvikling, selv om en slik utvikling ved UNN strengt tatt ikke kan leses ut av våre tall.

Mangelen på økning i forskningsaktivitet ved UNN er et uttrykk for at forskningen taper kampen med klinikken om ressursene. Årsaken til dette er at den kliniske virksomhetens ressursbehov er umettelige og oppleves som absolutte. Dersom forskningen skal styrkes, må man være forberedt på å nedprioritere noen kliniske behov til fordel for forskning. Dette forutsetter igjen en erkjennelse av at klinikk og forskning prinsipielt har samme siktemål, nemlig bedre pasientbehandling, om enn i forskjellig tidsperspektiv. Ledere må erkjenne at flere ressurser må brukes på forskning $\mathrm{i}$ dag for å oppnå bedre behandling i fremtiden. Konflikten mellom forskning og klinikk må styres med klare strategiske mål som utgangspunkt.

Det er usikkert i hvilken grad konklusjonene fra denne undersøkelsen kan generaliseres til de andre universitetsklinikkene. Når det gjelder forskningsaktiviteten bedømt ved publikasjonspoeng på regionalt helseforetaksnivå, opplever Helse Øst og Helse MidtNorge en reduksjon i sine andeler av poengene som Helse Nord, mens Helse Sør og Helse Vest øker sine andeler (12). Dette er uttrykk for at forholdene på universitetsklinikkene varierer. Når det gjelder konflikten mellom bruk av ressurser mellom kliniske aktiviteter og forskning er det imidlertid liten grunn til å tro at det er store forskjeller mellom universitetsklinikkene.

Forfatterne vil takke medarbeidere ved Klinisk forskningssenter, UNN, for hjelp med den praktiske gjennomføringen av undersøkelsen. Vi er også takknemlige for hjelp fra Terje Bruen Olsen med a finne fram data fra NIFUs doktorgradsregister og for kommentarer fra medarbeidere og kollegaer som har lest gjennom manuskriptet.

Tabell 4. Faktorer som hindrer forskning og økning av forskningsaktivitet ${ }^{1}$.

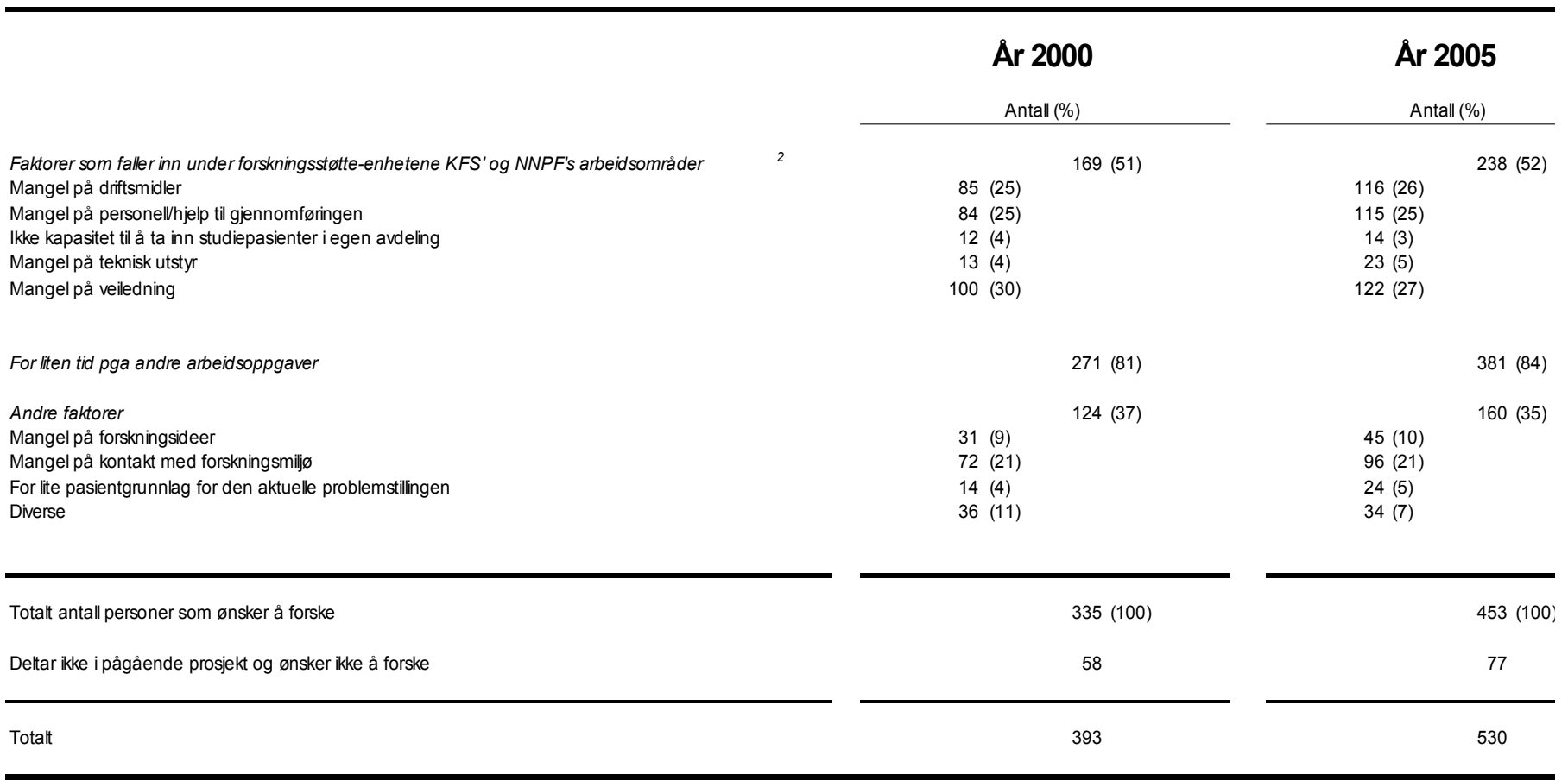

${ }^{1}$ Tallene representerer estimater for hver av de to populasjonene av alle spurte leger og psykologer på grunnlag av de besvarte spørreskjemaene. Det var anledning til å angi mer enn en faktor

${ }^{2}$ KFS og NNPF er UNNs forskningsstøtteenheter Klinisk forskningssenter og Nord-norsk psykiatrisk forskningssenter 


\section{REFERANSER}

1. Røttingen JA, Thorsby P, Seem C, et al. Medisinsk forskning ved norske universiteter. Tidsskr Nor Laegeforen 1998; 118 (15): 2339-2343.

2. Nes M, Røttingen JA. Leger og forskning - når er bunnen nådd? Tidsskr Nor Lageforen 2003; 123 (3): $344-$ 345.

3. Gilhus NE. God medisin forutsetter aktiv forskning. Tidsskr Nor Laegeforen 2001; 121 (25): 2913.

4. Aavitsland P. Mer eller bedre forskning? Tidsskr Nor Laegeforen 2002; 122 (25): 2427.

5. Røttingen JA. Ressursene til medisinsk forskning må dobles. Tidsskr Nor Lageforen 2005; 125 (9): 1220 1221.

6. Sørlie D, Wisborg T, Wahlby L, et al. Programmet Medisinsk forskning i Nord-Norge 1992-2001. Tidsskr Nor Lageforen 2005; 125 (4): 449-450.

7. Norges forskningsråd. Nøkkeltall for medisinsk og helsefaglig forskning. http://www.forskningsradet.no/ CSStorage/Flex_attachment/Nokkeltall2003.pdf (8.1.2006).

8. Høie IM. Klinisk forskning i de regionale helseforetakene. Tidsskr Nor Laegeforen 2002; 122: 2660.

9. Eriksen BO, Evensen E. Hvilke tiltak kan øke forskningsaktiviteten ved universitetssykehusene? Tidsskr Nor Lageforen 2001; 121 (25): 2960-2963.

10. Särndal CE, Swensson B, Wretman J. Model assisted survey sampling. New York: Springer-Verlag, 2005.

11. Øk de økonomiske rammene for Helse Nord. Pingvinen 27.2.2004.

12. Helsedepartementet. Oversikt over måleresultater fra de regionale helseforetakene for 2004. http://odin.dep. no/filarkiv/255347/Statistikk_budsjett2006_post78.xls (28.11.2005).

13. Regionale komiteer for medisinsk forskningsetikk. Publikasjoner fra Forskningsetiske komiteer. http://www. etikkom.no/HvaGjorVi/Publikasjoner (28.11.2005).

14 Gilhus NE, Hjortdahl P. Fordypningsstillinger er en forskningsressurs. Tidsskr Nor Laegeforen 2005; 125 (16): 2224-2225.

15. Nexø E, Werner S, Gerner T. Evaluering av MH-gruppen i Tromsø. Oslo: Norges forskningsråd, 1999. 